\title{
PROJETO DE EXTENSÃO MENINAS QUE ENGENHAM O FUTURO
}

\author{
Mariana Protti Spinato -mariana.spinato@sou.unijui.edu.br \\ Universidade Regional do Noroeste do Estado do Rio Grande do Sul - UNIJUÍ \\ Rua Lulu Ingelfritz, $N^{o} 480$, Bairro São Geraldo \\ CEP 98700000 - Ijuí(RS)
}

Taciana Paula Enderle - taciana.enderle@unijui.edu.br

Universidade Regional do Noroeste do Estado do Rio Grande do Sul - UNIJUÍ

Rua Lulu Ingelfritz, $N^{o} 480$, Bairro São Geraldo

CEP 98700000 - Ijuí(RS)

Caroline Daiane Radüns - caroline.raduns@unijui.edu.br

Universidade Regional do Noroeste do Estado do Rio Grande do Sul - UNIJUÍ

Rua Lulu Ingelfritz, $N^{o} 480$, Bairro São Geraldo

CEP 98700000 - Ijuí(RS)

Resumo: As universidades devem permitir-se interferir no espaço regional onde se encontram, através de projetos de extensão, compreendendo a cultura popular e trabalhando a partir das necessidades dos cidadãos. Um exemplo de ação extensionista é o projeto "Meninas que Engenham o Futuro", vinculado ao Departamento Ciências Exatas e Engenharias (DCEEng) da Universidade Regional do Noroeste do Estado do Rio Grande do Sul - UNIJUI, e contemplado pela chamada CNPq/MCTIC $N^{o} 31 / 2018$. O objetivo do projeto é produzir troca de saberes e a inclusão das mulheres nas engenharias, através da aproximação dos conceitos de engenharia ao dia a dia das estudantes da educação básica. O projeto é desenvolvido junto a cinco escolas da rede pública de Ijuí/RS e de Santa Rosa/RS e inclui estudantes do ensino básico, professoras da educação básica, estudantes da graduação de engenharia elétrica e engenharia química e professoras dos cursos de engenharia elétrica e química. Ações do projeto permitem discussões sob aspectos sociais e técnicos. Durante a participação no projeto, cada grupo de estudantes formula uma proposta para reduzir o consumo de energia elétrica e água da escola, e ações que visem se inserir na rotina e fazer das escolas. Este projeto permite desenvolver nas participantes seus potenciais nas ciências exatas e engenharias, sua capacidade de interferir no espaço escolar e consequentemente na cidade, além de estimular uma reflexão sobre as questões sociais nas diversas escalas, ou ainda no sentido mais amplo de sua importância, na educação.

Palavras-chave: Inclusão social. Extensão universitária. Engenharia. Energia elétrica. Água. 


\section{INTRODUÇÃO}

Investir em sistemas mais eficientes e projetos que fomentem ações de combate ao desperdício de água e energia proporcionam redução de custos para os consumidores e impactam positivamente na conservação dos recursos naturais. Se observado os ambientes públicos, possibilitar a redução dos valores das faturas de energia e água significa impactar nos cofres públicos. Nesse contexto, incorporar conceitos e conhecimentos nas escolas públicas, que possam facilmente ser convertidos em ações e que reforçam a conscientização sustentável de sujeitos, refletem positivamente, possibilitando, por exemplo, maior investimento em infraestrutura.

No entanto, o processo de educação ambiental requer um trabalho concreto, e que possa ser colocado em prática, além de multiplicado e replicado. Muitos são os desafios quando se fala de combate ao desperdício de energia elétrica e recursos hídricos. Apropriar-se desses conceitos e utilizá-los no dia a dia, é importante, porém requer que os usuários tenham um conhecimento técnico básico. Repassar esses conhecimentos, auxilia na promoção do desenvolvimento sustentável. Paralelamente a este trabalho de troca de conhecimento técnico, se une a discussões sobre a inserção das mulheres na área das ciências exatas e engenharias. Ou seja, mulheres estudando e atuando em área onde a predominância ainda é masculina.

Segundo dados apresentados em reportagem pelo portal de notícias da Globo, em 2015 as mulheres representavam 30,3\% das matrículas em curso de engenharia civil, a ainda menos, 26,9\% atuando no mercado de trabalho. Em 201720.813 pessoas fizeram o registro no conselho de engenharia civil, sendo 14.971 homens e 5.842 mulheres. Esses dados demonstram a realidade apenas do curso de engenharia civil, sendo que em outras engenharias a presença feminina é ainda menor. Muitas mulheres desistem de seguir cursos nessas áreas pelo preconceito ainda presente na sociedade de serem funções masculinas.

Unir questões técnicas e sociais é o tema norteador do Projeto Meninas que Engenham o Futuro, vinculado ao Departamento Ciências Exatas e Engenharias (DCEEng) da Universidade Regional do Noroeste do Estado do Rio Grande do Sul - UNIJUI, e contemplado pela chamada CNPq/MCTIC No 31/2018. O objetivo do projeto é produzir troca de saberes e a inclusão das mulheres nas engenharias, através da aproximação dos conceitos de engenharia ao dia a dia das estudantes da educação básica, que são o público alvo do projeto. A partir desta proposta, é possível estimular os sujeitos a explorar de forma clara conceitos de meio ambiente, desenvolvendo uma consciência ecologicamente responsável, da importância no que tange o uso racional de energia e recursos hídricos, além de trazer a tona o debate sobre o espaço das mulheres no fazer das mulheres nas ciências exatas e engenharias. Isto torna o público alvo do projeto um agente propulsor sobre as temáticas em seu meio, seja no ambiente escolar, em sua residência ou qualquer outro ambiente que frequente.

\section{METODOLOGIA}

Este projeto está incluso na linha qualitativa, através da abordagem teórica e prática. $\mathrm{O}$ universo do projeto abrange o trabalho com 5 escolas públicas, sendo 3 delas do município de Ijuí/RS, e duas delas do município de Santa Rosa/RS. Esse contexto, forma um grupo fixo, o 
qual é o público alvo, composto de: 15 estudantes da Educação Básica do sexo feminino matriculadas nas escolas públicas participantes, com bolsas de Iniciação Científica Júnior (ICJ); 5 professores da Educação Básica vinculados às escolas públicas participantes do projeto, com bolsa de Apoio Técnico à Extensão no País - Nível Superior (ATP-A).

Além deste grupo fixo, foram convidados a participar do projeto, mais 10 professores da educação básica e 15 estudantes da Educação Básica do sexo feminino. As atividades com o público alvo foram realizadas por 2 professoras do curso de engenharia elétrica e duas professoras do curso de engenharia química, da Unijuí, com o auxílio de 3 estudantes de graduação do sexo feminino matriculadas nos cursos de engenharias.

\subsection{Etapa 1}

Nesta etapa, o planejamento das atividades e desenvolvimento de materiais para as etapas subsequentes foram realizadas. Esse material inclui apresentações, apostilas, livro sobre eficiência energética e uso da água. Esse período também foi utilizado para orientação das 3 estudantes de graduação, as quais deram apoio durante as atividades das etapas seguintes.

A Figura 1 representa uma apresentação realizada no Dia 08 de março de 2019, dia internacional da mulher, no auditório da universidade em Ijuí, com todas escolas de Ijuí e Santa Rosa, e também algumas autoridades, com o intuito de marcar o início do projeto. Neste dia também foi realizado o cadastro das estudantes e professoras no curriculum lattes e plataforma Carlos Chagas.

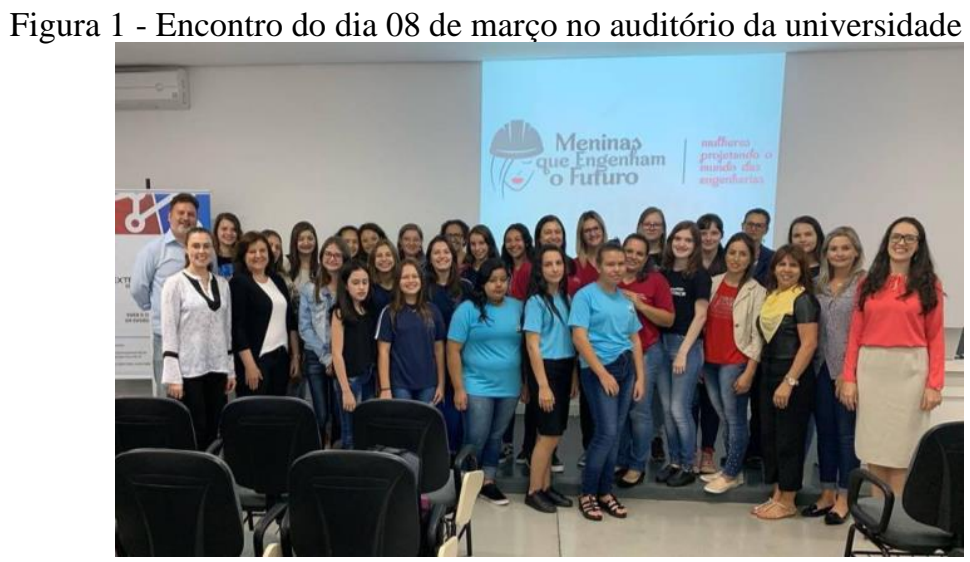

Fonte: Autoria Própria.

As alunas da graduação eram duas da Engenharia Elétrica e uma da Engenharia Química, com esses estudos, a aluna de graduação da Engenharia Química obteve conhecimentos sobre a parte de eficiência energética, geração de energia e segurança das instalações elétricas, assuntos não abordados em seu curso de graduação. Respectivamente, as estudantes de Engenharia Elétrica ampliaram sua visão acerca dos assuntos referens e reuso e tratamento de água, assuntos que não estão em seus currículos padrões. Esse intercâmbio de conhecimentos resultou na produção dos materiais. Ainda, as meninas foram desafiadas a desenvolverem textos e apresentações didáticas, visando a melhor compreensão das alunas da educação básica. Essa atividade contribuiu significativamente no crescimento das alunas de graduação. 


\subsection{Etapa 2}

Nesta etapa foi realizada orientações aos professores das escolas públicas, sendo o público alvo os professores de ciências, português e matemática.

As professoras de ciências e física foram estimuladas a relacionar os conteúdos ministrados, com a energia elétrica e abastecimento de água, bem como os conceitos e metodologias advindas dos cursos de engenharias, aplicadas nestes conteúdos.

Aos professores de português foi apresentado o modelo de projeto que as alunas usaram para confeccionar as etapas 4 e 6 . As professoras foram desafiadas a auxiliar as alunas na elaboração destes documentos.

As professoras de matemática conheceram os métodos de análise utilizados para a verificação do impacto econômico, com a adoção de conceitos de eficiência energética e uso racional da água. Esses métodos foram aplicados pelas alunas, nas etapas 4 e 6 .

As professoras da cidade de Ijuí tiveram a formação em momentos distintos das professoras de Santa Rosa. Porém, os dois grupos de professoras integralizaram 12 horas de atividades. Estas atividades foram nos laboratórios da Universidade.

\subsection{Etapa 3}

As estudantes participaram de palestras técnicas, com o objetivo de aplicar as atividades desenvolvidas na etapa 1. As alunas das escolas de Ijuí formaram um grupo de estudo, enquanto que as alunas das escolas de Santa Rosa formaram outro grupo de estudo.

As palestras foram ministradas pelas professoras e alunas da graduação. Para as alunas da graduação, ensinar os conteúdos e captar a atenção das estudantes da educação básica foi um desafio. Inicialmente, ministraram o conteúdo de forma mas estática em razão do nervosismo e falta de experiência. Com o passar das reuniões, desenvolveram maior habilidade para a fala em público e ensino dos conteúdos, realizando palestras mais dinâmicas e claras, com a interação das estudantes. Estas atividades foram nos laboratórios da Universidade, conforme pode-se observar na Figura 2.

Figura 2 - Palestra técnicas sobre Eficiência Energética

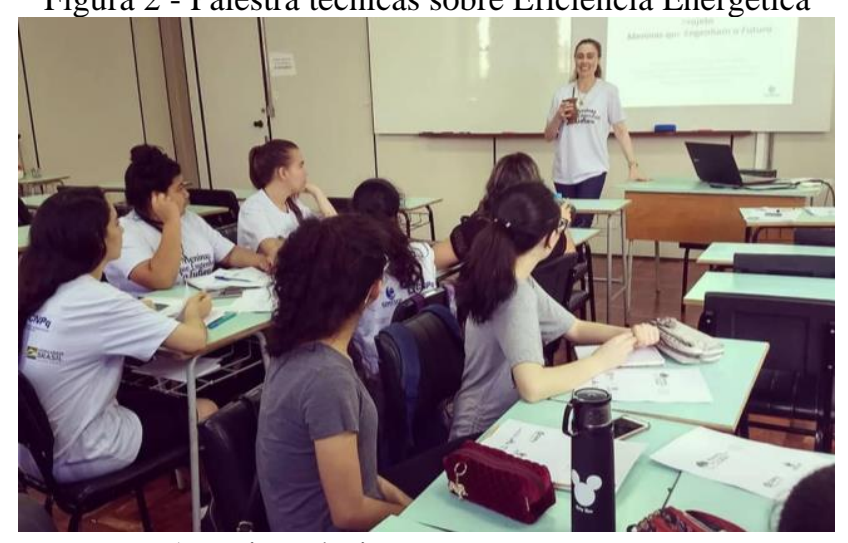

Fonte: Autoria Própria.

As professoras de ciências, física, matemática e português também foram convidadas a participar destas atividades. 


\section{COBENGE COBENGE 2020 da ABENGE}

O principal objetivo era repassar os seguintes conceitos às estudantes:

Energia elétrica:

- Definição dos conceitos de Eficiência e Eficácia;

- Análise do consumo de energia da escola;

- Estudo das ações que podem reduzir o consumo;

- Desenvolver o projeto de Eficiência Energética da escola.

Abastecimento de água:

- Definição dos conceitos de abastecimento de água, uso racional, reuso e reaproveitamento de água;

- Análise do consumo de água da escola;

- Estudo de alternativas para reduzir o consumo de água potável.

- Desenvolver o projeto de Uso Racional e Reaproveitamento de Água para a escola.

A Figura 3 mostra as alunas da educação básica participando de uma atividade prática no laboratório de engenharia química da universidade. A prática utilizada foi a simulação de tratamento de água, onde as estudantes tiveram a oportunidade de visualizar e entender todas as etapas do tratamento que ocorrem nas estações, e ver a importância de cada estágio. Isso gerou uma maior consciência acerca do reuso da água, pois foi demonstrado todos os processos que a água deve passar antes de retornar às residências e por isso não deve ser desperdiçada.

Figura 3 - Aula prática sobre tratamento de efluentes no laboratório de Engenharia Química da Universidade.

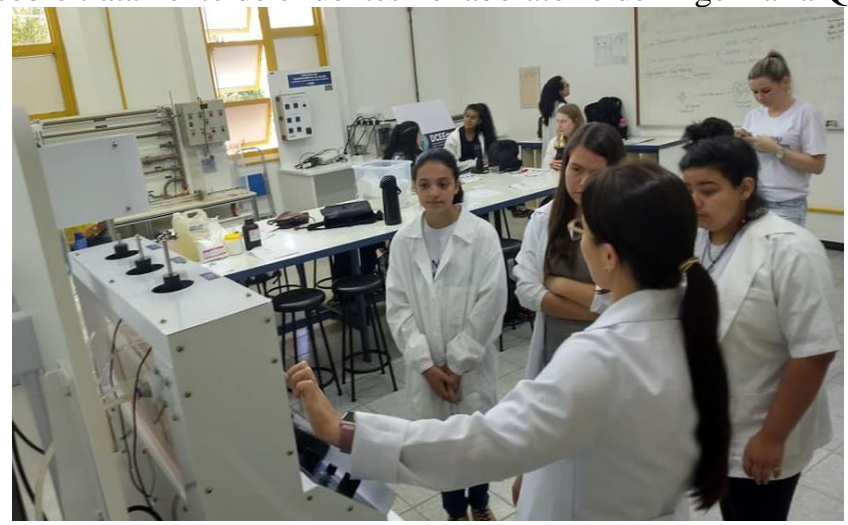

Fonte: Autoria Própria.

A Figura 4 representa uma visita do projeto a usina hidrelétrica localizada na cidade de Ijuí. A visita foi acompanhada por um responsável técnico que explicou como funcionava esse tipo de usina geradora de energia. Foi possível observar o curso da água e o maquinário utilizado nessa transformação de energia mecânica para elétrica. 


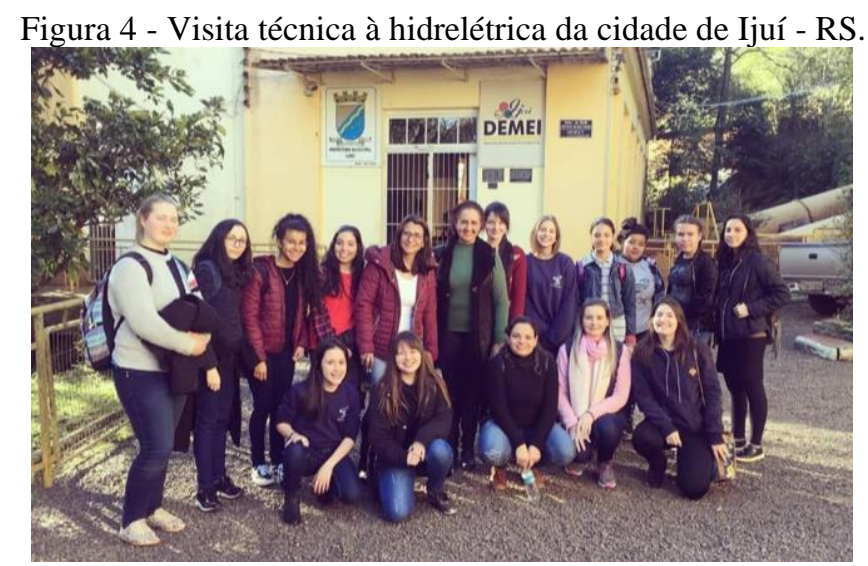

Fonte: Autoria Própria.

A Figura 5 mostra a visita do projeto a estação de tratamento de água da cidade de Ijuí. A visita foi acompanhada pela Química responsável pela estação, que explicou detalhadamente cada etapa do tratamento, demonstrando os locais em que ocorriam. Ainda, explicou sobre as análises que são realizadas para identificar a qualidade da água.

Figura 5 - Visita técnica à estação de tratamento de água da CORSAN.

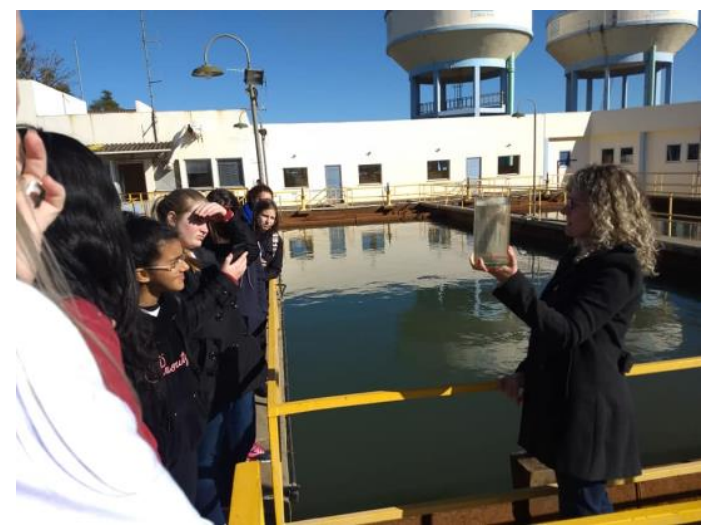

Fonte: Autoria Própria.

Nessa etapa, foram promovidas rodas de conversa sobre a história das mulheres na engenharia, a atuação no mercado de trabalho atual e a porcentagem feminina nas universidades em cursos de engenharias. As estudantes da educação básica foram instigadas a pensar a razão de ainda nos dias de hoje a porcentagem de mulheres cursando ciências exatas ainda era muito menor. E ainda, sobre a diferença salarial entre gêneros.

Foi reproduzido e discutido o filme "Estrelas Além do Tempo" que conta a história de uma equipe de mulheres afro americanas da NASA, lutando contra o preconceito e liderando uma das maiores operações tecnológicas da história americana. (SANTOS, 2019). Esta atividade possibilitou o diálogo sobre a importância que essas mulheres tiveram na luta de igualdade de gênero. 
As professoras e alunas dos cursos de engenharias contaram suas histórias e sua caminhada na área. Com isso foi observado diferentes histórias. Algumas tiveram o apoio na escolha do curso, outras já sentiram o preconceito. Isso foi importante para as estudantes da educação básica entenderem que pode haver esse preconcento mas que deve-se lutar contra isso e não deixar que impeça a escolha profissional.

Ainda, foram apresentadas histórias de mulheres que marcaram a engenharia, lutando contra os preconceitos da época. Entre elas, Mae Jemison, primeira astronauta negra a embarcar em uma viagem ao espaço e mais recente, Katie Bouman, uma das cientistas responsáveis pela primeira foto de um buraco negro (FEREGUETTI, 2018).

\subsection{Etapa 04}

Com o conhecimento obtido durante a Etapa 3, as alunas foram desafiadas a construir um projeto de eficiência energética para suas escolas, sendo isso apoiado pelas professoras, e com base no modelo de projeto apresentado na Etapa 3. Também foi realizado assessoramento às alunas, em suas próprias escolas. O período para esta atividade foi de 8 semanas.

As estudantes de graduação foram responsáveis por apresentar ideias de projetos para as meninas da educação básica, com isso buscaram alternativas sustentáveis e de baixo custo de instalação, para viabilizar os projetos. Isso contribuiu para a visualização de projetos reais e aplicados, muitas vezes não trabalhados em sala de aula.

\subsection{Etapa 05}

Com o projeto de eficiência energética finalizado, as estudantes fizeram a apresentação de seus resultados, sendo uma das apresentações no município de Ijuí, envolvendo as escolas deste município, e outra apresentação no município de Santa Rosa, com os projetos das escolas desta cidade. Contou com a participação dos alunos e professores das escolas envolvidas. A Figura 6 mostra as alunas da Escola Ruy Barbosa de Ijuí apresentando seu projeto de eficiência Energética.

Figura 6 - Escola Ruy Barbosa de Ijuí apresentando o projeto de eficiência energética.

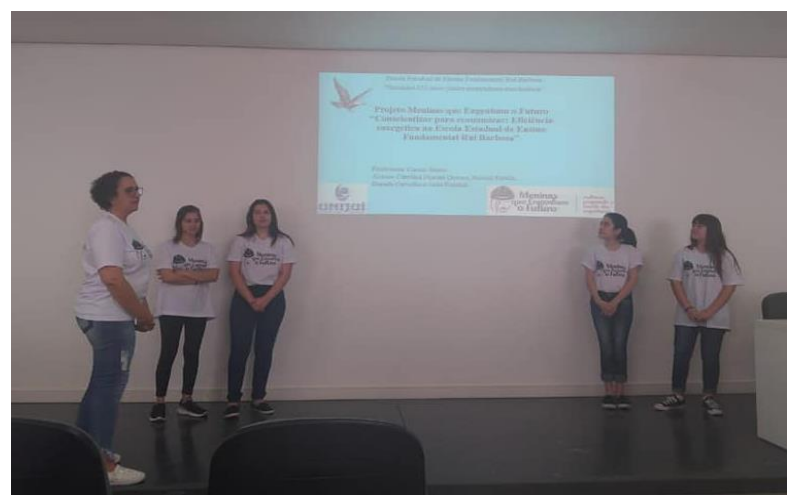

Fonte: Autoria Própria. 


\section{COBENGE COBENGE 2020 da ABENGE}

\subsection{Etapa 06}

Com o conhecimento obtido durante as etapas de formação, as alunas serão desafiadas a construir um projeto de uso racional e reaproveitamento de água para suas escolas, com o apoio e orientação das professoras, seguindo os conceitos e objetivos descritos na Etapa 3, além disso, realizou-se assessoramento às alunas em suas escolas.

\subsection{Etapa 07}

Com o projeto de uso racional e reaproveitamento de água finalizado, as estudantes fizeram a apresentação de seus resultados, sendo uma das apresentações no município de Ijuí, envolvendo as escolas deste município, e outra apresentação no município de Santa Rosa, com os projetos das escolas desta cidade. Contou com a participação dos alunos e professores das escolas envolvidas. A Figura 7 mostra as meninas do ensino fundamental e médio da Escola Coronel Bráulio de Oliveira de Santa Rosa apresentando seu projeto de reuso de água.

Figura 7 - Escola Coronel Bráulio Oliveira de Santa Rosa apresentando o projeto de reuso de água.

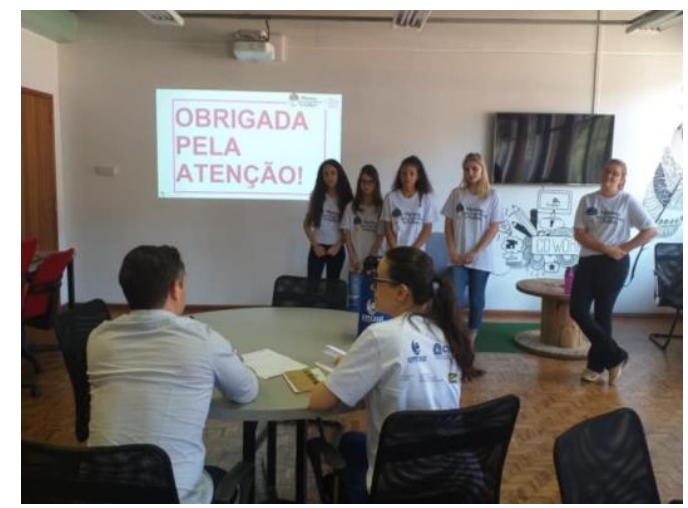

\subsection{Etapa 08}

Fonte: Autoria Própria.

Foi realizado um seminário, Figura 8, abrangendo o público alvo das 5 escolas, no qual houve o intercâmbio entre alunas e professoras, entre os municípios. $\mathrm{O}$ evento foi realizado no Campus da Universidade em Santa Rosa e teve como objetivo de apresentar os projetos confeccionados pelas alunas. Por fim, com a realização do seminário criou-se um núcleo de apoio nas escolas para manutenção das atividades desenvolvidas no projeto. 
Figura 8 - Seminário para apresentação final dos projetos no campus de Santa Rosa.

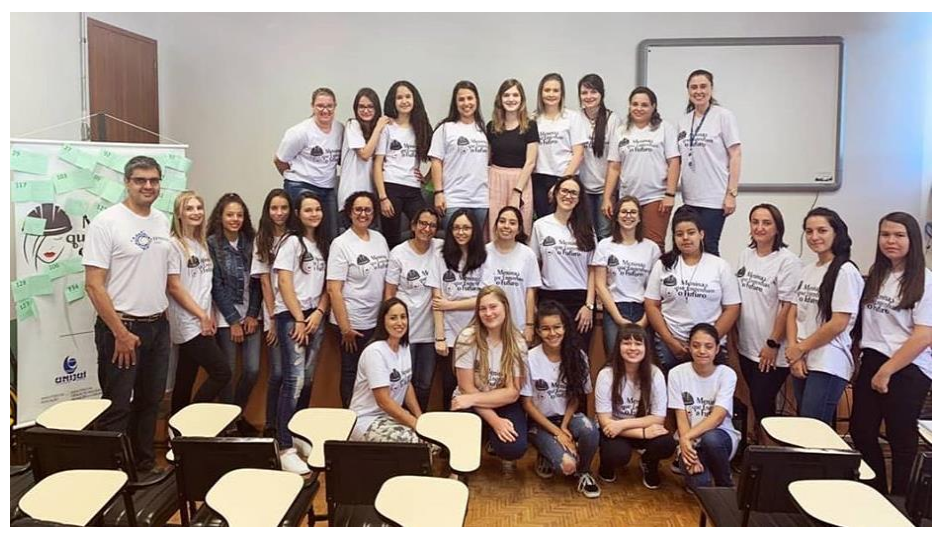

Fonte: Autoria Própria.

\section{CONSIDERAÇÕES FINAIS}

A partir de um intercâmbio de conhecimentos entre a universidade e a educação básica é possível abordar várias temáticas. Os conteúdos sobre eficiência energética e reuso da água transmitidos para as estudantes da educação básica se tornaram um pilar para a construção de um pensamento sustentável e criação de sistemas de eficiência energética e reuso de água para as escolas de Ijuí e Santa Rosa.

Observou-se uma evolução no envolvimento das estudantes com o projeto, mostrando problemas encontrados na comunidade em que vivem e possíveis soluções para os mesmos. Foram desafiadas a escrever e apresentar projetos de reuso da água e eficiência energética, o que contribuiu para o desenvolvimento intelectual.

Os debates acerca da história das mulheres nas engenharias e sua colocação nas universidades e no mercado de trabalho atualmente foi de extrema importância para as estudantes entenderem que ainda há um preconceito, fator que pode ser observado pela extrema diferença de estudantes do sexo masculino e feminino nos cursos de graduação na área das engenharias, e pelas diferenças de salários para mesmo cargo e função.

\section{Agradecimentos}

Ao CNPq pelo apoio financeiro e a $17^{\mathrm{a}}$ e $36^{\mathrm{a}}$ Coordenadorias Estaduais de Educação pela parceria.

\section{REFERÊNCIAS}

FEREGUETTI, Larissa. Mulheres que mudaram a Engenharia e a Ciência: Mae Jemison. Engenharia 360. 21 de outubro de 2018. Disponível em < https://engenharia360.com/mulheres-que-mudaram-a-engenharia-e-a-ciencia-mae-jemison/> . Acesso em 30 de julho de 2020. 
SANTOS, Greicielle. Pesquisa analisa o filme "Estrelas além do Tempo" e aponta silenciamento da voz feminina na ciência. Portal UFLA - Universidade Federal de Lavras. 11 de julho de 2019. Disponível em < https://ufla.br/noticias/pesquisa/13084-pesquisa-da-uflaanalisa-o-filme-estrelas-alem-do-tempo-e-aponta-como-a-voz-feminina-foi-silenciada-naciencia-durante-e-apos-a-corrida-espacial>. Acesso em: 30 de julho de 2020.

MORENO, Ana Carolina. Porcentagem de mulheres nas faculdades de engenharia civil cresce mais que $\mathrm{n}^{\mathbf{0}}$ de engenheiras no mercado. Portal de Notícias da Globo. 20 de setembro de 2017. Disponível em < https://g1.globo.com/educacao/guia-de-carreiras/noticia/porcentagem-demulheres-nas-faculdades-de-engenharia-civil-cresce-mais-que-n-de-engenheiras-nomercado.ghtml >. Acesso em: 30 de julho de 2020.

Quem é Katie Bouman, a cientista famosa pela foto do buraco negro?. TecMundo. 11 de abril de 2019. Disponível em < https://www.tecmundo.com.br/ciencia/140329-katiebouman-cientista-famosa-foto-buraco-negro.htm>. Acesso em: 30 de julho de 2020.

\title{
GIRLS EXTENSION PROJECT THAT ENGINE THE FUTURE
}

\begin{abstract}
Universities must allow themselves to interfere in the regional space where they find themselves, through extension projects, understanding popular culture and working from the needs of citizens. An example of an extension action is the project "Girls who engineer the future", linked to the Department of Exact Sciences and Engineering (DCEEng) of the Regional University of the Northwest of the State of Rio Grande do Sul - UNIJUI, and contemplated by the call CNPq / MCTIC $N^{o} 31$ / 2018. The objective of the project is to produce an exchange of knowledge and the inclusion of women in engineering, through the approximation of engineering concepts to the daily lives of basic education students. The project is developed with five public schools in Ijuí / RS and Santa Rosa / RS and includes students of basic education, teachers of basic education, undergraduate students of electrical engineering and chemical engineering and teachers of electrical engineering courses and chemistry. Project actions allow discussions on social and technical aspects. During participation in the project, each group of students formulates a proposal to reduce the consumption of electricity and water, and actions that will continue to happen over the years as part of the schools' activity routine. This project allows participants to develop their potentials in engineering and exact sciences, their ability to interfere in the school space and consequently in the city, in addition to stimulating a reflection on social issues at different scales, or even in the broadest sense of their importance, in education.
\end{abstract}

\section{Keywords:}

Social inclusion. University Extension. Engineering. Electricity. Water. 